\title{
Benign Mixed Tumor of the Vulva
}

National Cancer Institute

\section{Source}

National Cancer Institute. Benign Mixed Tumor of the Vulva. NCI Thesaurus. Code C40302.

A benign neoplasm that arises from the vulva and is characterized by the presence of epithelial cells forming nests and tubules in a fibrotic stroma. It may recur locally and complete excision is recommended. 